\title{
MÉTHODOLOGIE DE L'ÉTUDE ENDOCRINIENNE D'UNE ESPÈCE SAUVAGE, L'ANGUILLE.
}

\author{
Sylvie DUFOUR, J. MARCHELIDON, C. MILET, \\ B. QUERAT, C. SALMON.
}

Laboratoire de Physiologie Générale et Comparée, Muséum National d'Histoire Naturelle, URA 90 CNRS, 7 rue Cuvier, 75231 Paris Cedex 05, France.

\section{RÉSUMÉ}

L'étude des régulations hormonales, reponsables du contrôle de grandes fonctions telles que le développement, la croissance et la reproduction, présente chez l'anguille un intérêt tout particulier du fait du cycle biologique original de ce poisson. Les objectifs d'une telle étude sont à la fois fondamentaux (connaissance de la biologie de l'espèce, notion d'espèce modèle, écophysiologie, évolution) et appliqués (caractérisation des populations, maîtrise du cycle biologique).

Cependant, la complexité et la méconnaissance actuelle de ce cycle apportent des difficultés supplémentaires (absence de référence naturelle pour les caractéristiques physiologiques et environnementales des dernières étapes du cycle) qui s'ajoutent à celles concernant classiquement la mise en oeuvre d'une telle étude chez une espèce particulière (nécessité de la mise au point des outils spécifiques d'investigation), espèce de surcroît sauvage (hétérogénéité physiologique et génétique des animaux étudiés) et en danger (limitation du nombre d'animaux expérimentaux).

C'est la mise en oeuvre de tout un ensemble de méthodes d'investigation, allant de la mise au point des outils moléculaires (purifications d'hormones, obtention d'anticorps, dosages immunologiques, clonage, obtention de sondes...) à la réalisation d'expériences in vitro (cultures de cellules, incubation ou périfusion d'organes) et in vivo (ablations de glandes, traitements hormonaux, prélèvements sanguins...) juqu'aux études sur le terrain, qui permet une approche complète et intégrée de l'endocrinologie de ce poisson.

Mots-clés : endocrinologie, anguille, Anguilla anguilla, méthodes, hormone, purification, dosage, clonage, in vivo, in vitro.

\section{METHODS FOR ENDOCRINE STUDIES OF A WILD SPECIES, THE EEL.}

\begin{abstract}
Studying hormonal regulations which are responsible for the control of main functions such as development, growth and reproduction, is of special interest in the eel, due to the peculiar biological cycle of this fish. Such a study has both fondamental aims (knowledge of eel biology, use of the eel as a model, ecophysiology, evolution) and applied ones (characteristics of eel populations, control of eel biological cycle).

However, the complexity and the present lack of data on the eel biological cycle provide special difficulties (lack of natural references concerning the physiological characteristics and the environmental conditions of the last steps of the cycle), in addition to those encountered with the study of a peculiar species (need for development of specific research tools), a wild species (physiological and genetical heterogeneity of the animals) and an endangered species (limitation of the number of experimental animals).
\end{abstract}


The use of various investigation methods, including development of molecular tools (hormonal purification, antibodies production, immunological assays, cloning and probe obtention), in vitro (cell culture, organ incubation or perifusion) and in vivo (gland ablation, hormonal treatments, blood samples...) studies as well as field experiments, leads to a whole and integrative approach of eel endocrinology.

Key-words : endocrinology, eel, Anguilla anguilla, methods, hormone, purification, assay, cloning, in vivo, in vitro.

\section{A. BUTS ET PROBLÈMES DE L'APPROCHE ENDOCRINIENNE CHEZ L'ANGUILLE}

\section{Projet fondamental et appliqué}

\subsection{Hormones et récepteurs}

L'Endocrinologie représente l'étude des régulations assurées dans l'organisme par des messagers chimiques, les hormones. Les hormones sont synthétisées par des organes particuliers (les glandes endocrines) et véhiculées par le sang jusqu'aux organes cibles, dont elles contrôlent l'activité. Les tissus cibles possèdent des récepteurs, molécules capables de lier spécifiquement l'hormone, ce qui assure la spécificité de la régulation. La liaison de l'hormone au récepteur entraîne toute une cascade d'événements intracellulaires, dont la formation de seconds messagers, aboutissant aux effets finaux (division, différenciation ou modification d'activité de la cellule cible) (Figure1).

\subsection{Buts fondamentaux}

Les régulations hormonales sont responsables du contrôle de fonctions essentielles de l'organisme telles que développement, croissance, métabolisme, osmorégulation, métamorphose, reproduction. Leur étude est donc indispensable à la connaissance de la biologie d'une espèce.

De plus, certaines espèces peuvent présenter, outre leur intérêt propre, un intérêt fondamental général du fait de régulations particulièrement spectaculaires (notion d'espèce modèle) ou du fait de relations particulières de leur cycle biololgique avec l'environnement (intérêt écophysiologique) ou de leur position dans l'évolution des espèces (intérêt évolutif). C'est le cas de l'anguille dont le cycle biologique présente des événements marquants, tels que les deux métamorphoses (la métamorphose larvaire et l'argenture) et le blocage prépubertaire de la fonction de reproduction (DUFOUR, 1986), qui en font une espèce "modèle" ; de même, la totale dépendance de la maturation sexuelle vis-à-vis des facteurs environnementaux offre un intérêt particulier écophysiologique. Enfin, les hypothèses sur la mise en place, au cours de l'évolution, de ce cycle migratoire exceptionnel apportent un intérêt évolutif considérable (voir articles de S. DUFOUR et de Y.A. FONTAINE, ce numéro).

\subsection{Buts appliqués}

Du point de vue appliqué, l'étude des régulations hormonales chez l'anguille présente plusieurs intérêts majeurs :

- la participation, à côté des descriptions anatomiques, à la caractérisation des animaux et des différentes étapes du cycle biologique. II s'agit, par exemple, de l'étude que nous entreprenons actuellement avec le CSP pour caractériser les stades jaune et argenté ainsi que les étapes de l'argenture qui mènent de l'un à l'autre (voir article de Y.A. FONTAINE, ce numéro). Les variations hormonales impliquées dans cette métamorphose peuvent représenter, pour le gestionnaire, la base de l'élaboration d'outils de caractérisation des populations des eaux continentales (proportion du stock prêt à migrer, état physiologique des animaux sédentaires et migrants...). Une étude de ce type devrait être entreprise également dans le futur pour la caractérisation des anguilles du point de vue du sexe génétique et phénotypique.

- la participation à la connaissance des impacts des modifications de l'environnement (par exemple, l'effet de pollutions ou de parasites) sur l'état sanitaire des animaux, en apportant le point de vue patho-physiologique. 


\section{Milieu extracellulaire}

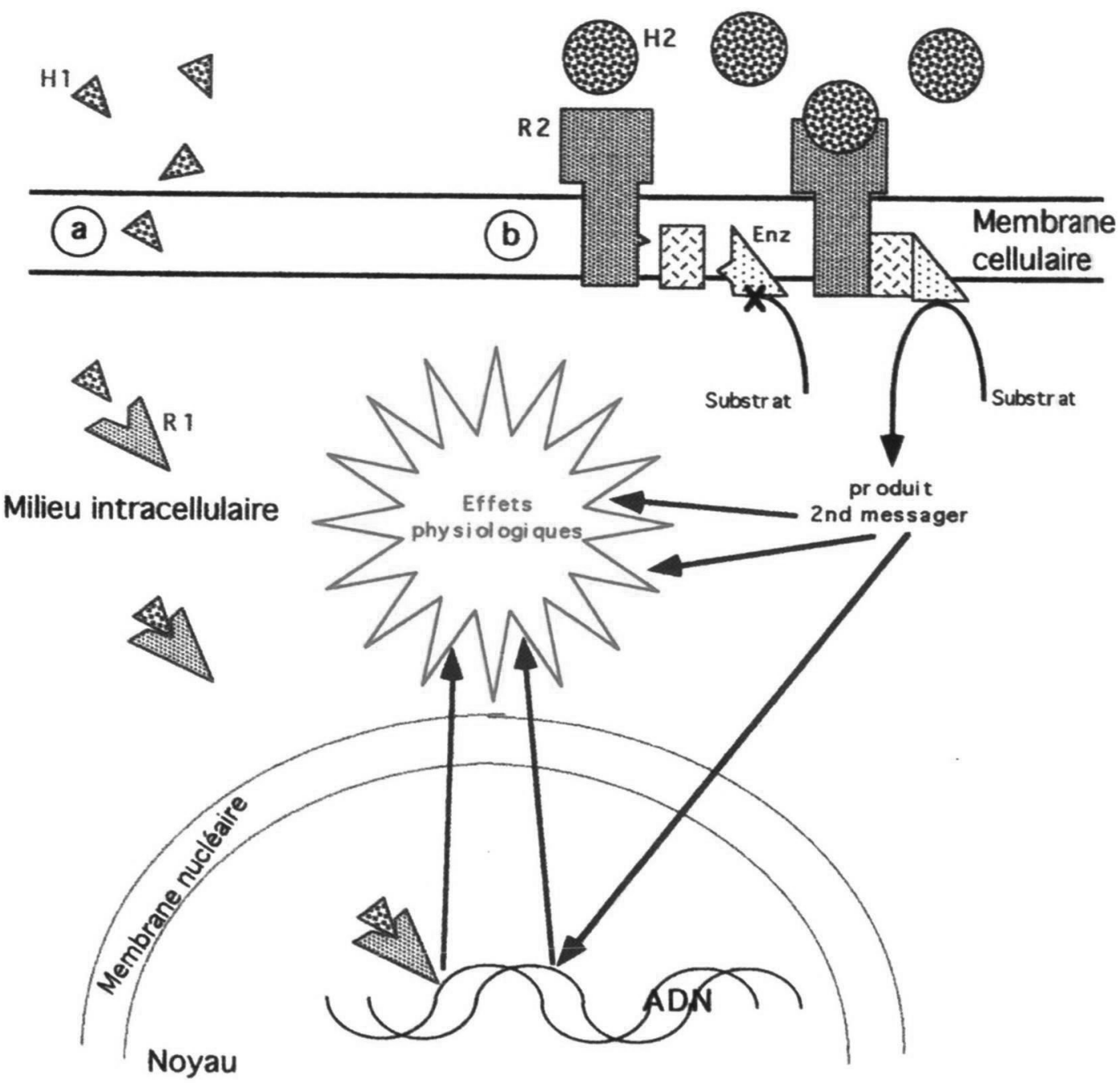

Figure 1 : Présentation schématique de divers mécanismes d'action hormonaux.

Chaque hormone (H) agit sur son (ses) organe(s) cible(s) en se fixant de façon spécifique et réversible sur une protéine particulière, le récepteur (R). Quelques récepteurs (a : R1), par exemple ceux des hormones stéroïdes, sont intracellulaires et capables de se déplacer, une fois liés à l'hormone, vers le(s) site(s) précis de l'action hormonale. D'autres récepteurs (b : R2), par exemple ceux des hormones gonadotrope et thyréotrope, sont dans la membrane cellulaire ; la liaison de l'hormone sur leur extrémité extracellulaire entraîne l'activation d'enzymes (Enz) et la production de seconds messagers relayant l'information hormonale.

Figure 1 : Schematic presentation of various hormonal mechanisms of action.

Each hormone (H) acts on its target organe(s) through specific binding to a special protein, the receptor (R). Some receptors (a: R1), e.g. those of steroid hormones, are intracellular and, when bound to the hormone, able to move towards the precise site(s) of hormone action. Other receptors (b: R2), e.g. those of gonadotropin and thyrotropin, are within the cell membrane; binding of the hormone to their extracellular ending leads to the activation of enzymes (Enz) and production of second messengers which relay hormonal information. 
- l'ouverture vers une maîtrise d'étapes-clefs du cycle vital par la manipulation expérimentale des régulations hormonales : il peut s'agir de la métamorphose larvaire (leptocéphale en civelle), de la différenciation sexuelle, de la croissance, de la seconde métamorphose (argenture), de la maturation sexuelle et de la reproduction.

\section{Méthodes de l'approche endocrinienne}

\subsection{Les méthodes classiques de l'endocrinologie}

Les méthodes qui ont permis la mise en évidence des régulations hormonales chez de nombreuses espèces consistent classiquement à rechercher l'effet, sur les tissus cibles, de l'ablation de glandes endocrines ou, inversement, de l'administration d'extraits de ces glandes. La purification, à partir de ces extraits glandulaires, des principes actifs sur les tissus cibles permet ensuite la caractérisation des molécules hormonales.

La mise au point de dosages spécifiques offre la possibilité de mesurer les taux hormonaux avec leurs variations naturelles ou expérimentales. Pendant longtemps, ces dosages ont été basés sur la réponse du tissu cible à l'action hormonale (dosages biologiques in vivo sur l'animal, puis in vitro sur le tissu cible isolé) ; plus récemment, se sont largement développés les dosages immunologiques (radioimmunologiques puis immunoenzymatiques), basés sur la reconnaissance de l'hormone par des anticorps spécifiques. Ces dosages présentent l'avantage d'être facilement mis en oeuvre et d'être très sensibles ; ils n'excluent pas cependant l'intérêt propre des dosages biologiques, en particulier dans le cas d'hormones protéiques de grande taille pour lesquelles des modifications de la conformation de la molécule peuvent entraîner des variations de son activité biologique sans affecter significativement sa reconnaissance antigénique par l'anticorps.

\subsection{Les méthodes récentes}

En plus des méthodes précédemment citées, se sont récemment très largement développées des méthodes d'investigation à l'échelle cellulaire et moléculaire. L'action des hormones est maintenant étudiée au niveau de l'unité fonctionnelle du tissu cible : la cellule. Ces études permettent d'analyser les étapes successives de l'action hormonale, depuis la liaison au récepteur jusqu'à la réponse finale (Figure 1). Les techniques de génétique moléculaire ont particulièrement élargi les possibilités d'investigations, aussi bien d'un point de vue fondamental (étude des régulations au niveau génomique) qu'appliqué (caractérisation et production des molécules hormonales ; transformations géniques).

\subsection{L'intégration des différents niveaux d'étude}

Le développement considérable actuel des moyens d'investigation cellulaire et moléculaire ne doit pas laisser de côté les approches plus traditionnelles, qui conservent tout leur intérêt propre pour la compréhension des régulations au sein de l'organisme ainsi que pour l'étude du rôle des facteurs environnementaux. Ainsi, la connaissance des régulations hormonales chez une espèce comme l'anguille doit intégrer les différents niveaux d'investigation, depuis l'étude moléculaire jusqu'à l'étude des animaux sur le terrain.

\section{Problèmes méthodologiques propres à l'étude de l'anguille}

\subsection{Une espèce originale : des méthodes à développer}

L'étude endocrinienne d'une espèce particulière, comme l'anguille, ne permet pas de disposer de toute la panoplie de méthodes et d'outils disponibles pour une espèce beaucoup plus couramment étudiée comme par exemple le rat ! Une telle étude nécessite donc la mise au point des méthodes d'investigation. Pour les études in vivo, il s'agit par exemple d'opérations chirurgicales, de techniques de prélèvements sanguins ou d'administration d'hormones. Pour les études in vitro, il faut définir les milieux d'incubation des tissus cibles et établir les techniques de préparation et culture des cellules. Enfin, il faut développer les outils moléculaires : purification, caractérisation, clonage d'hormones et de leurs récepteurs, mise au point des dosages. 
Certaines hormones ne posent cependant pas de problème car leur structure, relativement simple, est totalement consenvée chez l'ensemble des vertébrés, ce qui rend possible l'utilisation des systèmes de dosage déjà commercialisés : il s'agit par exemple des hormones stéroïdes (comme l'estradiol ou la testostérone) ou des hormones thyroïdiennes.

En revanche, la majorité des hormones, de nature protéique (c'est-à-dire constituées d'un enchaînement, codé génétiquement, d'acides aminés), présentent des différences interspécifiques dues à l'évolution génique ; ces variations sont souvent suffisamment importantes pour nécessiter la caractérisation des hormones et la mise au point des dosages pour chaque espèce étudiée.

\subsection{Une espèce sauvage : des difficultés supplémentaires} son étude:

L'anguille, en tant qu'espèce sauvage, présente deux difficultés particulières pour

- tant que la reproduction et l'ensemble du cycle biologique de l'anguille n'auront pas été maîtrisés, toutes les expérimentations devront être réalisées sur des individus prélevés dans les populations naturelles ; ce prélèvement doit donc être restreint pour ne pas représenter lui-même un risque supplémentaire pour cette espèce déjà menacée (BRUSLE, 1990). Cette restriction rend impossible, par exemple, la purification de certaines hormones qui sont en concentration extrêmement faible (c'est le cas de l'hormone gonadotrope hypophysaire et de certaines neurohormones cérébrales).

- les expérimentations sont réalisées sur des individus sauvages et non sur des animaux provenant d'élevages bien caractérisés génétiquement et physiologiquement comme cela est le cas chez le rat ou, à un certain degré, chez des poissons comme la truite, le poisson-rouge, etc... Les anguilles prélevées dans les populations naturelles présentent donc des différences physiologiques (telles que l'âge, les effets des conditions environnementales antérieures) et génétiques qui entraînent des variations individuelles importantes dans leur état et dans leurs réponses aux traitements expérimentaux : ces variations représentent une difficulté pour la reproductibilité et l'interprétation des résultats, d'autant plus que le nombre d'animaux expérimentaux doit être restreint comme nous venons de le mentionner.

\subsection{Les inconnues du cycle : absence de modèle naturel}

L'absence encore aujourd'hui de captures d'anguilles lors de la migration océanique et sur le site de ponte fait que le dernier stade naturel accessible à l'observation et à l'expérimentation est le stade argenté, encore sexuellement immature (voir article de $S$. DUFOUR, ce numéro). Nous ne disposons donc d'aucun modèle naturel pour déterminer les modalités des régulations hormonales de la reproduction de l'anguille (nature et taux des hormones impliquées, chronologie de leur production, etc...) ni pour comparer les résultats de nos traitements expérimentaux avec l'état des animaux dans les conditions naturelles. Nous devons donc agir en aveugle, sans modèle biologique de référence.

De la même façon, la méconnaissance des conditions de la migration océanique et du site de ponte nous maintient dans le domaine des hypothèses pour toutes les études concernant les modalités de contrôle, par les facteurs environnementaux, des régulations hormonales de la reproduction. Ceci est d'autant plus crucial que la maturation sexuelle de l'anguille, au delà du stade argenté, est justement un phénomène entièrement dépendant des facteurs environnementaux (voir article de S. DUFOUR, ce numéro). Là encore, nous devons donc pour le moment expérimenter en aveugle, sans modèle environnemental de référence.

\section{B. MISE AU POINT DES OUTILS MOLÉCULAIRES}

\section{Purifications hormonales}

\subsection{Techniques de purification des hormones protéiques}

La purification d'une hormone peut être effectuée à partir de prélèvements des glandes qui la produisent. La purification consiste en la séparation de l'hormone des autres 
constituants de la glande, ce qui est réalisé par des méthodes basées sur les différences de propriétés physico-chimiques des molécules : par exemple, séparation selon leur solubilité (par précipitation sélective), selon leur taille (par filtration sur tamis moléculaire), selon leur charge électrique (par électrophorèse), etc...

Une purification nécessite en général la combinaison de plusieurs types de séparations, pouvant avoir des rendements allant de près de $100 \%$ à moins de $10 \%$. Ainsi, plus la purification nécessite d'étapes, plus faible sera la quantité de produit obtenu. II est donc nécessaire de disposer au départ d'un stock d'organes important, ce qui pose un problème, lorsqu'on travaille sur une espèce sauvage comme l'anguille pour laquelle les prélèvements sur les populations naturelles doivent être restreints.

\subsection{Techniques de caractérisation des hormones purifiées}

Afin de s'assurer que l'hormone purifiée n'est plus contaminée par aucun autre composant et qu'elle a conservé son activité biologique au cours des différents traitements de séparation, des caractérisations s'avèrent indispensables. Une partie du produit purifié doit être utilisé à cet effet. Le contrôle de pureté peut être effectué par la visualisation d'une bande unique en électrophorèse et ne nécessite que quelques microgrammes de produits. L'activité biologique est étudiée par des tests in vivo ou, préférentiellement, in vitro pour utiliser une moindre quantité d'hormone.

Enfin, les techniques récentes de microséquençage, qui nécessitent une centaine de microgrammes, permettent de déterminer la séquence en acides aminés des extrémités de la protéine ou de fragments de celle-ci après digestion enzymatique : cette méthode offre la possibilité à la fois de s'assurer de la pureté de l'hormone, de vérifier sa nature (par comparaison avec les structures connues des mêmes hormones chez d'autres espèces de poissons ou de mammifères) et de déterminer des séquences partielles qui seront à la base de la fabrication de sondes pour les techniques de biologie moléculaire.

\subsection{Exemples de purification d'hormones hypophysaires d'anguille}

L'hypophyse est une glande endocrine d'importance majeure, située à la base du cerveau, et produisant plusieurs types d'hormones impliquées dans la régulation des grandes fonctions de l'organisme telles que croissance, métamorphose, reproduction.

Chez l'anguille, nous avons récemment réalisé la purification de deux hormones hypophysaires:

- l'hormone de croissance $(\mathrm{GH})$, protéine impliquée dans le contrôle de la croissance et qui joue aussi un rôle, chez les poissons, dans le contrôle de la reproduction et de l'osmorégulation ;

- l'hormone thyréotrope (TSH), glycoprotéine composée de deux sous-unités $\alpha$ et $\beta$, qui stimule l'activité d'une autre glande endocrine, la thyroïde, et qui est impliquée, par l'intermédiaire des hormones thyroïdiennes; dans le contrôle du développement, de la croissance, du métabolisme et de la métamorphose. Nous aurions souhaité pouvoir également purifier l'hormone gonadotrope (GTH), une autre glycoprotéine de structure similaire à celle de la $\mathrm{TSH}$, et qui joue un rôle essentiel dans la régulation de la fonction de reproduction en contrôlant l'activité des gonades ; mais sa teneur hypophysaire est beaucoup trop faible, du fait de l'état immature des anguilles (voir article de S. DUFOUR, ce numéro), pour pouvoir en réaliser la purification.

A partir d'un millier d'hypophyses d'anguilles (précieusement collectées depuis de nombreuses années à l'occasion d'expérimentations au laboratoire ou lors de campagnes de prélèvements sur des sites d'exploitation de l'anguille), nous avons pu réaliser la purification de la TSH et de la $\mathrm{GH}$, après trois étapes de séparation (selon le poids moléculaire, la charge électrique et la solubilité) (MARCHELIDON et al., 1991). Quelques milligrammes de $\mathrm{GH}$ et quelques centaines de microgrammes de TSH purifiées ont été obtenus ! Une caractérisation partielle de la séquence en acides aminés de la $\mathrm{GH}$ et des sous-unités $\alpha$ et $\beta$ de la TSH a été réalisée par la technique de microséquençage (MARCHELIDON et al., 1991). II s'agit de la première TSH purifiée chez un poisson ; la 
situation physiologique particulière de l'anguille, si elle représente un obstacle pour la purification de la GTH (du fait de sa très faible teneur hypophysaire), a en revanche facilité la purification de la TSH en évitant les contaminations en GTH (hormone structuralement très proche).

\section{Obtention d'anticorps et applications}

L'obention d'hormone pure permet de produire des anticorps dirigés spécifiquement contre elle et de développer des dosages immunologiques pour l'étude des modifications des taux de cette hormone, au cours d'étapes importantes de la vie de l'animal ou sous l'effet de traitements expérimentaux. Les anticorps, utilisés en histologie, permettent aussi la visualisation des cellules produisant l'hormone : c'est l'immunohistochimie.

\subsection{Validation de dosages déjà en oeuvre}

Certaines hormones, comme les hormones thyroïdiennes ou les stéroïdes gonadiques, peuvent avoir une structure chimique identique depuis les poissons jusqu'aux Mammifères. Dans ce cas, une simple validation, chez le poisson, des techniques de dosage déjà mises en oeuvre chez les Mammifères est nécessaire. De plus, ces hormones et les anticorps correspondants sont commercialement disponibles. Chez l'anguille, nous mettons ainsi couramment en oeuvre au laboratoire des dosages radioimmunologiques des hormones thyroïdiennes (T3 et T4) (LELOUP et DE LUZE, 1980) et des stéroïdes sexuels (estradiol et testostérone) (LELOUP-HATEY et al., 1985).

Parmi les hormones de nature peptidique, la structure de certaines peut être également conservée et permettre l'utilisation d'anticorps déjà produits pour d'autres espèces : c'est le cas par exemple des neurohormones cérébrales de type gonadolibérine $(\mathrm{G} n \mathrm{RH})$ qui sont chez l'anguille identiques pour l'une à la GnRH mammalienne et pour l'autre à l'une des $\mathrm{GnRH}$ aviaires. La purification de ces deux neurohormones, malgré leur très faible concentration cérébrale, avait pu être réalisée chez des mammifères et oiseaux d'abattoir grâce aux quantités non limitées de cerveaux disponibles pour ces espèces. Par la suite, la caractérisation des séquences de ces hormones et leur simplicité (10 acides aminés) a permis leur synthèse chimique à grande échelle et la production d'anticorps ; ce sont de tels anticorps qui nous sont fournis par différentes équipes de recherche (J. KING et R. MILLAR, République d'Afrique du Sud ; R. PETER, Canada ; G. TRAMU, France ; F. VANDESANDE, Belgique) et que nous pouvons utiliser chez l'anguille (DUFOUR et al., 1993 ; MONTERO et al., sous presse).

D'autres hormones protéiques présentent des variations interspécifiques mais qui peuvent être dans certains cas suffisamment limitées pour permettre l'utilisation d'anticorps et de dosages développés pour une autre espèce. On utilise alors le terme de dosage hétérologue. Une validation rigoureuse de l'emploi de ce dosage hétérologue doit être réalisée : il s'agit en particulier d'une étude de la spécificité du dosage vis-à-vis des autres hormones de l'espèce hétérologue et d'une comparaison, pour cette espèce, des résultats des dosages immunologique et biologique. Chez l'anguille, nous utilisons ainsi pour l'hormone gonadotrope (GTH) un dosage hétérologue (DUFOUR et al., 1983) développé par BURZAWA-GERARD et KERDELHUE (1978) pour la GTH de carpe : la forte teneur hypophysaire en GTH chez la carpe avait en effet permis à E. BURZAWA-GERARD (1971) d'en réaliser la purification pour la première fois chez un poisson.

\subsection{Obtention d'anticorps}

Pour la majorité des hormones protéiques, seules des préparations de certaines espèces mammaliennes sont commercialement disponibles et les anticorps contre celles-ci ne réagissent pas avec les hormones de poissons. Un anticorps dirigé contre la GH bovine, par exemple, ne reconnaitra pas la GH d'anguille. Ceci est dû à des différences importantes dans la séquence protéique. Les différences peuvent même être telles qu'aucune réaction croisée n'est observée entre deux espèces de poissons : c'est le cas pour la GH entre les Salmonidés et l'anguille. L'unique solution est de préparer l'anticorps à partir de l'hormone purifiée et caractérisée. 
Nous avons ainsi préparé récemment, en collaboration avec J. L. HOUDEBINE (INRA), des anticorps contre la GH d'anguille. Pour cela, 200 à 300 microgrammes d'hormone pure sont nécessaires et ont été injectés à des lapins par voie sous-cutanée, après couplage de la $\mathrm{GH}$ avec une grosse protéine, l'ovalbumine, afin d'augmenter l'antigénicité, et en présence d'adjuvant de Freund, afin d'augmenter la réponse immunitaire.

\subsection{Mise au point de dosages radioimmunologiques}

Les dosages immunologiques reposent sur la réaction de liaison spécifique entre antigène et anticorps.

Les dosages radioimmunologiques (RIA = Radio Immuno Assay) mettent en oeuvre des réactions de compétition entre l'antigène présent dans les échantillons à doser (par exemple : extraits de glandes endocrines, sérum) et l'antigène purifié et marqué avec un atome radioactif (le traceur), vis-à-vis de la liaison avec un anticorps spécifique. La réaction se fait en tube, la fraction de traceur liée à l'anticorps est séparée de la fraction libre par immunoprécipitation (utilisation d'un deuxième anticorps dirigé contre le premier), et mesurée au moyen d'un compteur à radioactivité. Plus la quantité d'antigène de l'échantillon est importante, plus la fraction de traceur liée est faible. Les mesures sont rapportées à une courbe standard, représentant l'inhibition de la liaison du traceur à l'anticorps par des doses croissantes d'une préparation de référence de l'antigène.

Au laboratoire, nous mettons en oeuvre couramment pour l'anguille des RIA pour lesquels traceurs et anticorps sont disponibles commercialement : RIA de l'estradiol, de la testostérone, des hormones thyroïdiennes T3 et T4.

Nous avons aussi développé des RIA d'hormones peptidiques. II faut dans ce cas mettre au point et réaliser la technique de marquage du traceur : comme l'antigène est de nature peptidique, on peut utiliser le marquage à l'lode 125, dont l'atome est substitué à un atome d'hydrogène d'un résidu amino-acide tyrosine. Les conditions de la réaction de substitution (catalyse chimique ou enzymatique) et de la séparation du traceur de l'excès d'lode 125 libre doivent être mises au point pour chaque antigène. Cette réaction de marquage, qui met en jeu des quantités élevées de radioactivité, nécessite l'utilisation de locaux et d'équipements spécialisés. La deuxième étape de la mise au point du RIA consiste à la caractérisation des anticorps (affinité et spécificité de la liaison de l'antigène). Pour le dosage des hormones d'anguille, nous avons ainsi mis au point au laboratoire les RIA des deux gonadolibérines cérébrales (type mammalien : mGnRH et type aviaire : cGnRH-II) (DUFOUR et al., 1993), de la gonadotropine hypophysaire (GTH) (dans un système hétérologue de carpe; DUFOUR et al., 1983) et récemment de l'hormone de croissance hypophysaire (GH) (MARCHELIDON et al., 1994).

Les RIA sont très spécifiques, précis et reproductibles, et offrent la possibilité de traiter un grand nombre d'échantillons (plusieurs centaines par dosage). lls présentent l'inconvénient de l'utilisation de la radioactivité et d'équipements lourds de laboratoire (centrifugeuse, compteurs de radioactivité). Quand les propriétés de l'antigène et de l'anticorps le permettent, on essaie donc de substituer aux RIA des dosages immunoenzymatiques, de mise en oeuvre plus aisée et éventuellement applicables sur le terrain.

\subsection{Mise au point de dosages immunoenzymatiques}

Le test "ELISA" (Enzyme Linked Immunosorbent Assay) est un moyen rapide et précis de dosage d'anticorps ou d'antigènes. Une des méthodes employées est la suivante: une quantité définie d'antigène est fixée par adsorption sur les parois des puits d'une plaque de titration. L'anticorps spécifique, dit de première couche, préalablement incubé avec l'échantillon (contenant l'antigène à doser), est ajouté dans les puits. Plus l'échantillon contient d'antigène, plus la quantité d'anticorps libre et donc capable de se lier à l'antigène fixé aux puits sera faible. L'excès d'anticorps non lié est éliminé par lavage des puits. Un anticorps dit de deuxième couche, dirigé contre l'anticorps de première couche et couplé à un enzyme (peroxydase, phosphatase alcaline), est alors ajouté et sa présence est détectée 
par addition d'un chromogène (substrat incolore transformé par l'enzyme en produit coloré). La quantité d'anticorps fixés est alors déterminée par mesure de la densité optique.

Ce dosage tend à remplacer le dosage radioimmunologique en raison de sa simplicité de mise en oeuvre, de l'absènce d'utilisation de radioélément et de sa disponibilité permanente, ce que ne permet pas le RIA puisque la radiolyse impose une préparation fréquente de l'hormone marquée (tous les quinze jours pour certains antigènes peptidiques).

Certaines variantes du test ELISA permettent de greffer de façon covalente l'antigène sur la paroi des puits au bout d'un bras de liaison, afin de respecter la structure de la protéine antigénique et ainsi de laisser totalement accessibles aux anticorps ses déterminants antigéniques. Un système d'amplification du signal (système avidine/biotine) permet d'augmenter la sensibilité du dosage. Lorsque l'on dispose d'anticorps spécifiques des deux extrémités de la protéine, un dosage de type "sandwich" peut être utilisé, permettant d'augmenter grandement sa spécificité.

Pour l'anguille, nous avons mis au point des dosages ELISA pour les molécules de type PTH (hormone de type parathyroïdien, synthétisée par les corpuscules de Stannius et impliquée dans la régulation de la calcémie) et de type PTHrp (PTH related peptide). L'utilisation de dosages de type "sandwich" nous permet de distinguer ces différents types moléculaires. Le dosage de la vitellogénine d'anguille est également réalisé par ELISA (voir article de E. BURZAWA-GERARD et al., ce numéro).

\subsection{Utilisation des anticorps en immunohistochimie}

L'utilisation d'anticorps dirigés contre les molécules hormonales permet la visualisation des cellules productrices et la mise en évidence de variations dans leur activité. Le principe est similaire à celui décrit plus haut pour les ELISA : les coupes de tissus sont incubées avec le premier anticorps, dirigé contre la molécule hormonale et qui se fixe donc spécifiquement à l'hormone contenue dans les cellules. Cet anticorps est ensuite révélé grâce à un deuxième anticorps dirigé contre le premier et lui-même couplé à une enzyme (comme par exemple la peroxydase) qui catalyse la transformation d'un chromogène. Cette technique peut être appliquée à l'échelle de la microscopie optique et électronique.

Chez l'anguille, nous appliquons cette technique à la visualisation de nombreux types cellulaires produisant des hormones ou des neurohormones : par exemple les cellules hypophysaires produisant l'hormone gonadotrope (voir Point $C \S 2.2$. et Figure 3 : photo $C$ ), les neurones contrôlant l'activité hypophysaire, tels que les neurones à gonadolibérine (MONTERO et al., sous presse) et à GABA (MEDINA et al., 1994).

\section{Clonage et applications}

\subsection{Principe}

Les techniques de biologie moléculaire introduites à partir de la fin des années 1970 dans l'étude de l'endocrinologie ont permis de débloquer un grand nombre de verrous: d'une part, elles ont donné accès à la structure primaire de protéines très faiblement représentées et d'autre part, elles ont grandement facilité l'étude des mécanismes contrôlant la synthèse des protéines.

Rappelons (Figure 2) que les protéines sont «codées» par des gènes (situés sur les chromosomes, dans le noyau de la cellule) suivant un mécanisme complexe qui peut être schématisé de la manière suivante : le gène, molécule d'acide désoxyribonucléique (ADN), est tout d'abord "transcrit» dans le noyau en une molécule d'acide ribonucléique (ARN), copie du gène. L'ARN primaire subit un processus de maturation et l'ARN messager qui en résulte passe dans le cytoplasme de la cellule et se fixe sur les ribosomes. Ces particules vont "traduire" I'ARN messager en protéine. En effet, pour une partie de la molécule, appelée région codante, les ribonucléotides constituant l'ARN messager sont organisés en triplets, les codons. Chaque codon correspond à un acide aminé donné (c'est le code génétique universel). Les ribosomes "lisent» la succession des triplets et associent 
Bull. Fr. Pêche Piscic. (1994) 335 : 147-169 - 156 -
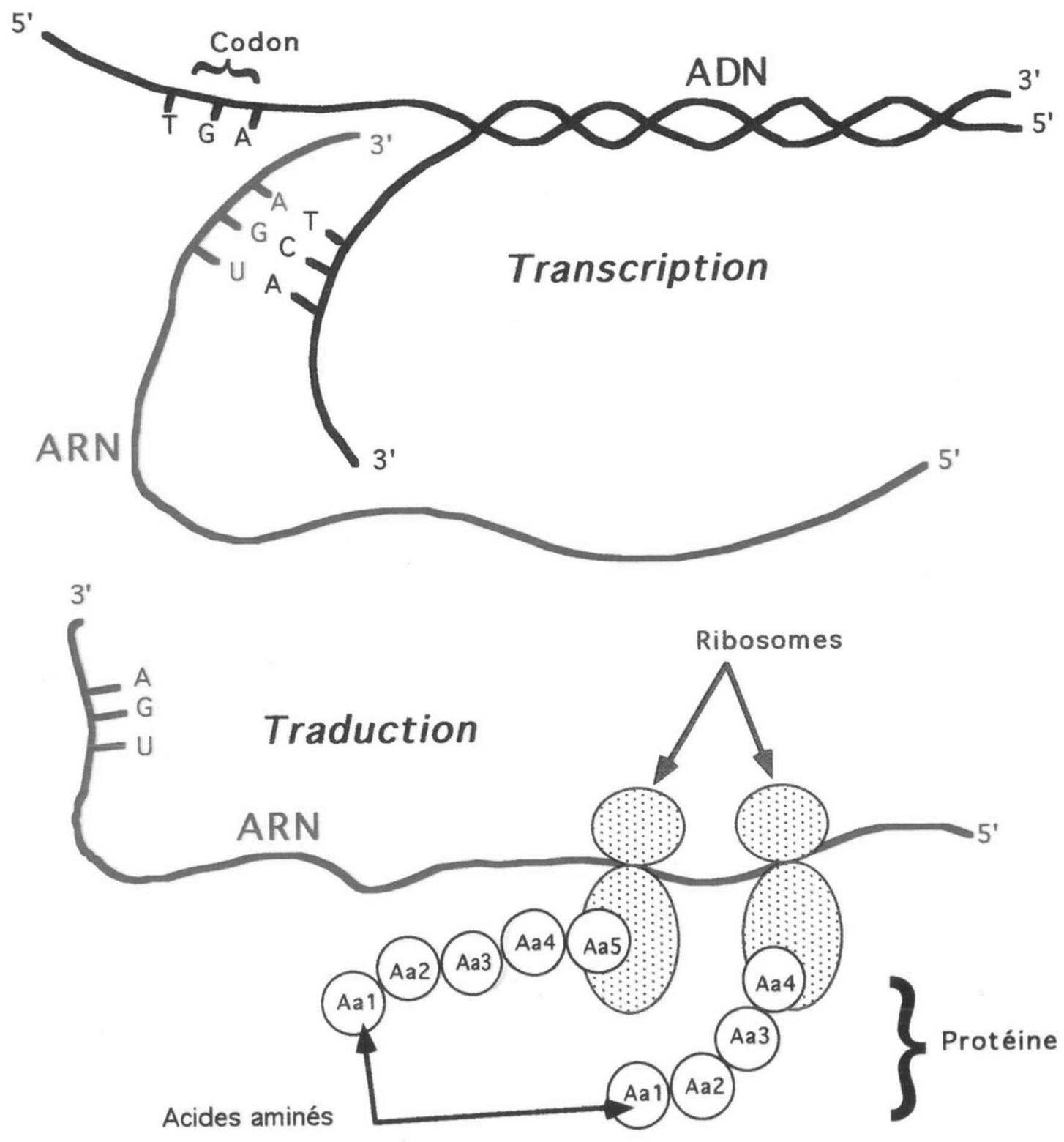

Figure 2 
Figure 2 : Les protéines sont codées par des gènes.

Le gène est le matériel nucléaire qui contient le code d'une protéine. Il est fait de deux brins d'acide déoxyribonucléique (ADN) enroulés en double hélice. Chaque brin d'ADN est une chaîne orientée de quatre constituants de base, les déoxynucléotides symbolisés par $A, T, G$ et $C$. Les deux brins s'apparient par complémentarité : ils utilisent la capacité de $A$ et $T$, d'une part, et de $\mathbf{G}$ et $C$, d'autre part, d'engager des liaisons entre brins pour construire la double hélice.

Transcription : une molécule intermédiaire, l'acide ribonucléique (ARN) messager, intervient dans la synthèse des protéines. Sa structure rappelle un brin d'ADN mais ses constituants, les ribonucléotides, sont différents et notés $A, U, G$ et $C$. Ils respectent cependant la complémentarité, $U$ remplaçant T. L'ARN messager est produit dans le noyau par une enzyme qui copie, par complémentarité, un des brins du gène.

Traduction : l'ARN messager passe dans le cytoplasme où des structures complexes - les ribosomes - le traduisent en protéine. A chaque triplet successif de ribonucléotides, ou codon, correspond un acide aminé et un seul ; les ribosomes lisent la succession des codons et enchaînent les acides aminés correspondants, ce qui conduit à la synthèse de la protéine.

Figure 2 : Proteins are encoded by genes.

Gene is the nuclear material which contains the code for a protein. It is made of two strands of deoxyribonucleic acid (DNA, ADN in the figure) each of them coiled around the other in a double helix. Each DNA strand is a chain of four basic components - the deoxyribonucleotides symbolised $A, T, G$ and $C$. Both strands pair one to the other by complementarity : they use the ability of $A$ and $T$, on one hand, and of $C$ and $G$, on the other hand, to form bonds between strands to build the double helix.

Transcription : an intermediary molecule, the messenger ribonucleic acid (RNA, ARN in the figure), takes place in protein synthesis. Its structure reminds a DNA strand but its components - the ribonucleotides - are different and noted $A, U, G$, and $C$. However they respect complementarity, $U$ substituting for T. The messenger RNA is produced within the nucleus by an enzyme which copies one strand of the gene by complementarity.

Translation : messenger RNA proceeds to the cytoplasm where complex structures - the ribosomes - translate it into the protein. To each serie of three nucleotides - a codon - corresponds one single aminoacid ; ribosomes "read" the successive codons and link up the corresponding aminoacids thus building the protein. 
successivement les acides aminés correspondants, constituants de base des protéines. La séquence nucléotidique d'un ARN messager donné permet donc de déduire la séquence en acides aminés de la protéine pour laquelle il code.

Les techniques de biologie moléculaire permettent de purifier et d'amplifier considérablement la quantité d'un ARN messager donné : il s'agit du clonage. Schématiquement, les ARN messagers sont extraits du tissu qui synthétise la protéine d'intérêt. Ces ARN sont "recopiés" sous forme d'ADN (ADN complémentaires) par un processus inverse de celui de la transcription. Les ADN complémentaires peuvent être insérés dans des "vecteurs de clonage" (en général, des virus bactériens modifiés, les bactériophages) qui, une fois intégrés dans une bactérie, vont se multiplier. L'ensemble des phages contenant les ADN complémentaires constitue ce que l'on appelle une "banque», spécifique du tissu duquel ont été extraits les ARN messagers. Les phages ayant inséré l'ADN d'intérêt (les clones) sont identifiés par “criblage", isolés et amplifiés (voir Applications). La séquence de l'ADN inséré peut alors être facilement décryptée. L'ADN complémentaire étant une copie à l'identique de l'ARN messager, la séquence peptidique peut être déduite de la séquence nucléotidique en utilisant le code génétique universel.

Comme nous l'avons déjà souligné plus haut dans le cas des purifications hormonales, les prélèvements sur les populations naturelles doivent être restreints : dans le cas du clonage, la technique d'amplification enzymatique (Polymerase Chain Reaction : PCR) permet d'avoir accès à des séquences d'ADN ou d'ARN à partir de très peu de matériel. En se basant sur une séquence protéique partielle de la protéine à cloner ou sur la connaissance de régions de la séquence bien conservées au cours de l'évolution, on peut synthétiser des amorces nucléotidiques, encadrant la séquence à cloner. La PCR consiste à utiliser ces amorces, en présence d'ADN ou d'ARN de l'échantillon et d'une enzyme (ADN polymérase, résistante à la température), pour copier, au cours de cycles thermiques successifs, la séquence encadrée par les amorces. Chaque cycle double le nombre de copies : au bout de 30 cycles, on amplifie en théorie la séquence d'un facteur $2^{30}$, soit près d'un milliard de fois. En fait, le rendement pratique est beaucoup plus faible mais suffisant pour déterminer la séquence et, si nécessaire, préparer une sonde moléculaire qui permettra de cribler une banque (cf. plus haut). Cette méthode de PCR nous a permis de cloner et séquencer la TSH $\beta$ d'anguille (SALMON et al., 1993) et est actuellement utilisée pour rechercher chez l'anguille les séquences des hormones de type PTH et PTHrp ainsi que celle du récepteur ovarien de la GTH.

\subsection{Application à la caractérisation de la séquence des hormones protéiques : exemple des hormones gonadotrope et thyréotrope}

Les techniques de biologie moléculaire ont été utilisées pour connaître la séquence des sous-unités $\alpha$ et $\beta$ de l'hormone gonadotrope (GTH), dont la concentration hypophysaire est trop faible pour permettre sa purification, ainsi que de celles de la TSH, dont la quantité purifiée n'a permis d'obtenir que des séquences partielles.

Une banque d'ADN complémentaires a été constituée à partir d'ARN messagers extraits de quelques dizaines d'hypophyses d'anguilles. Cette banque a été "criblée» par hybridation avec des «sondes» radioactives capables, chacune, de reconnaître par complémentarité une des différentes sous-unités de la GTH et de la TSH : en ce qui concerne la sous-unité $B$ de la TSH, la sonde correspondait à un fragment d'ADN synthétisé par PCR, codant pour une partie de la séquence de la sous-unité obtenue par le séquençage protéique partiel préalable. Dans le cas de la sous-unité $B$ de la GTH, la sonde correspondait également à un fragment d'ADN synthétique, codant pour une région peptidique particulièrement conservée au cours de l'évolution de cette famille d'hormones. Dans le cas de la sous-unité $\alpha$ commune à GTH et TSH, la sonde était constituée par un fragment de l'ADN complémentaire de la sous-unité $\alpha$ du rat, dont la séquence est suffisamment proche pour qu'il puisse y avoir une complémentarité partielle.

Les phages recombinants constituant la banque sont introduits dans des bactéries qui sont réparties sur un milieu de culture gélosé. Les phages se multiplient à l'intérieur de chaque bactérie puis, après avoir induit la lyse (la destruction de la membrane) de la bactérie, vont infecter les bactéries avoisinantes, conduisant à des plages de lyse 
facilement localisables sur le tapis bactérien. Les phages ainsi libérés des bactéries sont "transférés" sur une membrane de nylon, appliquée directement à la surface de la gélose. Après traitement adéquat, la sonde est mise en présence de la membrane et va se fixer, par complémentarité, sur l'ADN des phages ayant inséré l'ADN complémentaire de la sous-unité correspondante. La membrane est ensuite mise en contact avec un film d'autoradiographie : la radioactivité émise par la sonde impressionne le film, ce qui permet de localiser les plages de lyse correspondantes. Les clones sont purifiés, amplifiés, et la séquence en nucléotides déterminée. Les séquences en acides aminés des sous-unités $\alpha$, GTH $\beta$ et TSH $\beta$ ont ainsi pu être caractérisées chez l'anguille (QUERAT et al., 1990 a,b; SALMON et al., 1993).

Ces séquences peuvent être comparées aux séquences des hormones correspondantes des différents Vertébrés : des arbres des relations phylétiques peuvent être construits, permettant de reconstituer l'histoire, au cours de l'évolution, de ces familles d'hormones (QUERAT, 1994).

\subsection{Application à l'étude de la biosynthèse hormonale : dosage des ARN messagers}

Comme nous l'avons vu plus haut, la synthèse d'une protéine nécessite, en premier lieu, la synthèse de son ARN messager. L'ADN complémentaire permet d'estimer le taux de d'ARN messager correspondant présent dans la cellule.

Plusieurs techniques ont été développées pour quantifier un ARN messager donné. Parmi celles-ci, l'analyse en "Northern blot» est la plus utilisée (Figure 3 : photo D). Les ARN messagers sont extraits du tissu et séparés suivant leur taille (par électrophorèse) : les ARN, qui sont des acides, donc chargés négativement, migrent dans un champ électrique vers le pôle positif à une vitesse qui dépend de leur longueur : plus ils sont grands, plus ils sont retardés par la maille du gel. Une membrane de nylon (le "blot») est ensuite appliquée sur le gel et les ARN sont transférés sur la membrane par simple capillarité. Les ADN complémentaires clonés sont alors utilisés comme sonde, après marquage par un nucléotide radioactif. Mis en contact avec la membrane, ils vont s'hybrider par complémentarité sur les ARN correspondants : cela permet de détecter les ARN recherchés. Après autoradiographie, le «signal» est quantifié par densitométrie : son intensité est proportionnelle à la quantité de radioactivité émise, donc à la quantité d'ADN complémentaire hybridé, donc, enfin, à la quantité de l'ARN correspondant.

Nous appliquons cette technique chez l'anguille à l'étude des variations des teneurs en ARN messagers de la prolactine (QUERAT et al., 1994), des sous-unités de l'hormone gonadotrope (QUERAT et al., 1991) et de celles de l'hormone thyréotrope (PRADET$B A L A D E, 1994)$ en réponse à des changements physiologiques, à des modifications environnementales ou sous l'effet de traitements hormonaux.

\subsection{Utilisation des sondes en hybridation in situ}

En histologie, de même que l'application des anticorps permet de visualiser les cellules produisant les hormones, l'utilisation des sondes, qui s'hybrident aux ARN messagers, permet de détecter les cellules qui produisent ces ARN messagers. Des mesures de l'intensité du signal permettent également une estimation quantitative de la concentration en ARN par cellule et donc de détecter des variations d'activité. L'hybridation in situ peut être utilisée seule, en particulier quand l'obtention d'hormone pure et la production d'anticorps n'ont pu être réalisées. Utilisée en conjonction avec l'immunohistochimie, elle permet de comparer les capacités de la cellule à transcrire l'ARN messager et à le traduire en protéine, ces deux fonctions n'étant pas obligatoirement corrélées. Ces techniques peuvent être également utilisées pour la visualisation des tissus cibles par la détection des ARN messagers codant pour le récepteur hormonal.

Avec B. VIDAL, nous avons récemment mis au point et appliqué cette technique d'hybridation in situ à la visualisation chez l'anguille des cellules hypophysaires à prolactine (QUERAT et al., 1994) et à hormone thyréotrope (PRADET-BALADE, 1994) ainsi qu'à la détection des cellules cibles de la dopamine, possédant des ARN messagers pour le récepteur de type D1 (CARDINAUD et al., 1994). 


\subsection{Application à la production d'hormone recombinante}

Lorsque la purification d'une hormone n'est pas réalisable, ou lorsque les quantités nécessaires sont trop importantes (par exemple, pour des traitements chroniques in vivo, en recherche fondamentale ou appliquée, ou pour la fabrication d'anticorps), il peut être possible de les produire par «génie génétique».

Différents moyens ont été développés, utilisant divers organismes suivant le type et la quantité de protéine à produire. La technique consiste à faire fabriquer la protéine par cet organisme en ajoutant à son patrimoine génétique un gène artificiel codant pour la protéine (d'où le terme de protéine recombinante). Ce gène est construit en associant l'ADN complémentaire codant pour la protéine à des éléments permettant l'“expression" de ce gène dans l'organisme considéré (c'est la construction d'un vecteur d'expression, spécifique d'un organisme donné). Dans le cas le plus simple, tous les éléments nécessaires à la production de la protéine sont présents dans une bactérie. Dans ce cas, le vecteur d'expression contenant l'ADN complémentaire de la protéine à produire est introduit dans la bactérie et celle-ci est mise en culture. Les bactéries, dont le patrimoine génétique est ainsi transformé, se multiplient en produisant la protéine en quantité considérable. Dans certains cas, la production de la protéine ne peut être faite par des bactéries. En effet, certaines protéines n'adoptent leur structure définitive qu'après association avec d'autres éléments, notamment des sucres, une réaction que seule des cellules d'organismes plus évolués sont capables de réaliser. C'est le cas, par exemple, des glycoprotéines comme les sous-unités de la GTH ou de la TSH. Plusieurs types de cellules sont utilisées à cet effet comme certaines cellules d'insectes ou de mammifères cultivées in vitro. La méthode utilisée est basée sur le même principe mais nécessite des vecteurs d'expression différents, plus complexes, et conduisent à des quantités de protéine produite inférieures. Elles sont aussi plus onéreuses.

Chez l'anguille, ces techniques ont été appliquées, au Japon, à la production par des bactéries de l'hormone de croissance (GH) (SAITO et al.,1988).

\section{MISE AU POINT DES EXPÉRIMENTATIONS}

\section{Etudes in vivo}

\subsection{Importance des études in vivo}

Les régulations hormonales sont responsables du contrôle de fonctions, telles que croissance et reproduction, qui mettent en jeu un grand nombre d'organes; des systèmes hormonaux de contrôle et rétrocontrôle permettent un véritable dialogue entre les organes concernés. Par exemple, pour la reprodution (voir article de S. DUFOUR, ce numéro), les neurohormones cérébrales contrôlent la production hypophysaire d'hormone gonadotrope qui contrôle elle-même l'activité des gonades (production des gamètes et sécrétion des stéroïdes sexuels) ; les hormones stéroïdes activent de nombreuses fonctions périphériques (comme la production hépatique de vitellogénine chez la femelle ou la différentiation des caractères sexuels secondaires) mais elles exercent également des rétrocontrôles en régulant l'activité du cerveau et de l'hypophyse. Des études in vivo (sur l'organisme entier) sont donc indispensables à la compréhension de l'ensemble de ces régulations.

De plus, le rôle que peuvent jouer les hormones dans la médiation des effets des facteurs environnementaux sur les grandes fonctions de l'organisme rend également nécessaires des études in vivo sur le terrain, dans des conditions environnementales naturelles.

Toute une panoplie de méthodes d'intervention in vivo a été mise au point et est couramment en œuvre au laboratoire. Les anguilles ont une grande capacité à supporter l'émersion grâce à la protection de leurs branchies vis-à-vis de la déshydratation (à l'intérieur de la poche branchiale): dans les conditions naturelles, cette capacité permet aux anguilles de traverser des champs humides ou de franchir certains obstacles lors de leurs migrations ; dans les conditions de laboratoire, cette capacité nous permet la réalisation d'un grand nombre d'interventions hors de l'eau. 


\subsection{Prélèvements sanguins}

Les prélèvements sanguins peuvent être effectués de façon ponctuelle par prélèvement au moyén d'une seringue dans le vaisseau caudal. Cette intervention, rapide, ne nécessite pas d'anesthésie chez l'anguille, contrairement à un grand nombre de poissons étudiés en laboratoire (Cyprinidés, Salmonidés), ce qui présente l'avantage de ne pas perturber les fonctions cérébrales sensibles à l'anesthésie.

Pour des prélèvements répétés (par exemple, pour le suivi de la cinétique d'une décharge hormonale), ou pour le dosage d'hormones particulièrement sensibles au stress de l'émersion (par exemple, pour le cortisol), on procède préalablement à la pose d'un cathéter chez l'anguille anesthésiée, selon la méthode mise au point au laboratoire par LELOUP-HATEY (1976), puis on laisse l'anguille récupérer de l'anesthésie et de l'opération avant d'effectuer les prélèvements (Figure 3 : Photo A).

\subsection{Ablations de glandes}

Des opérations chirurgicales d'ablation de glandes endocrines sont réalisées chez l'anguille sous anesthésie. Dans tous les cas, des opérations-témoins, consistant en la même intervention (anesthésie, ouverture et fermeture, traitement antibiotique éventuel) sauf l'ablation elle-même, sont réalisées comme contrôle.

L'hypophysectomie est réalisée selon la méthode mise au point au Laboratoire par M. FONTAINE et O. CALLAMAND et décrite par LELOUP-HATEY (1964). Après incision de la muqueuse palatine, l'os sphénoïde est fraisé et l'hypophyse est aspirée. Le succès de l'opération est attesté au bout de quelques jours par la décoloration complète des anguilles due à la disparition de l'hormone hypophysaire mélanotrope.

La castration est particulièrement délicate chez l'anguille du fait de l'étendue des gonades (sur la moitié de la longueur du corps) et de leur attachement ferme aux parois du corps sur toute leur longueur, ce qui nécessite d'effectuer une ouverture très longue de la paroi du corps. Cette opération a pu être cependant mise au point avec succès au Laboratoire par N. LE BELLE chez le mâle et la femelle. Après l'ablation, la peau est recousue et la cicatrice soudée par une colle tissulaire ; les animaux reçoivent un traitement antibiotique préventif. Dans ces conditions, une très bonne survie a été observée et des expériences à long terme ont pu être menées (DUFOUR et al., 1989).

Sont également réalisées des ablations des corpuscules de Stannius, deux petites glandes endocrines situées sur les reins et sécrétant l'hormone de type PTH impliquée dans la régulation de la calcémie (LELOUP-HATEY, 1964).

\subsection{Traitements hormonaux}

Les traitements sont effectués par injections ou implants périviscéraux, des interventions rapides qui ne nécessitent chez l'anguille aucune anesthésie. On peut administrer les hormones elles-mêmes ou des molécules synthétiques agissant de façon similaire (agoniste) mais pouvant par exemple être éliminées moins rapidement de la circulation sanguine. On peut inversement traiter les animaux avec des agents bloquants de l'action hormonale (antagonistes), par exemple des molécules se fixant sur les récepteurs hormonaux et empêchant la liaison de l'hormone.

\subsection{Effet des facteurs externes en Laboratoire}

L'effet de certains facteurs environnementaux sur les régulations endocriniennes peut être étudié expérimentalement au Laboratoire :

— La salinité de l'eau peut être modulée à volonté avec des systèmes d'eau reconstituée en circuit fermé.

- La température et la lumière peuvent être contrôlées en plaçant les aquariums dans des pièces thermostatées et à éclairage et photopériode contrôlés.

Ces équipement sont couramment utilisés pour rechercher les effets des changements de salinité, de température ou de photopériode sur des productions hormonales chez l'anguille (par exemple : DUFOUR et FONTAINE, 1985 ; QUERAT et al., 
Bull. Fr. Pêche Piscic. (1994) 335 : 147-169 - 162 -
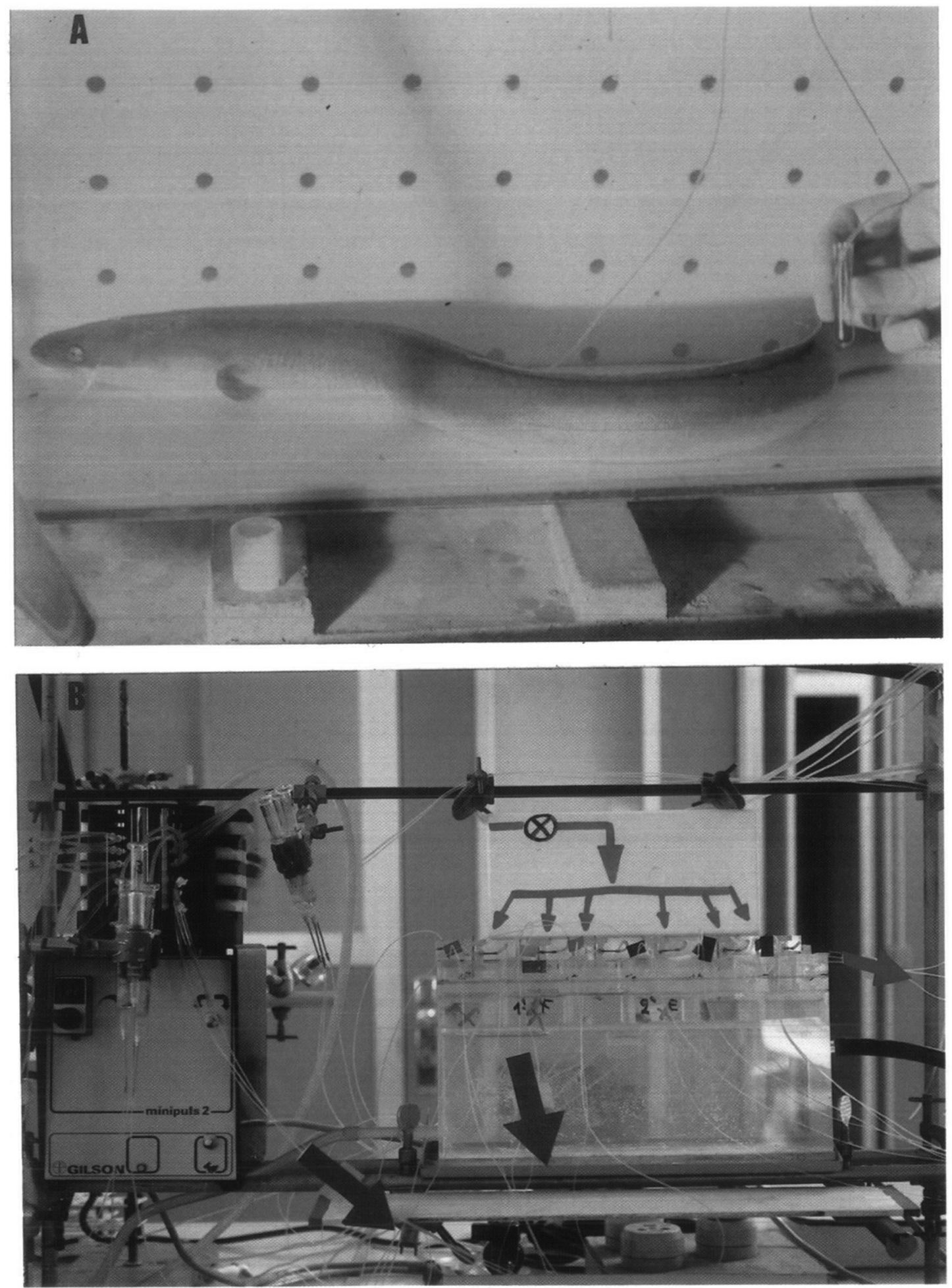

Figure 3 (Photos A et B) 


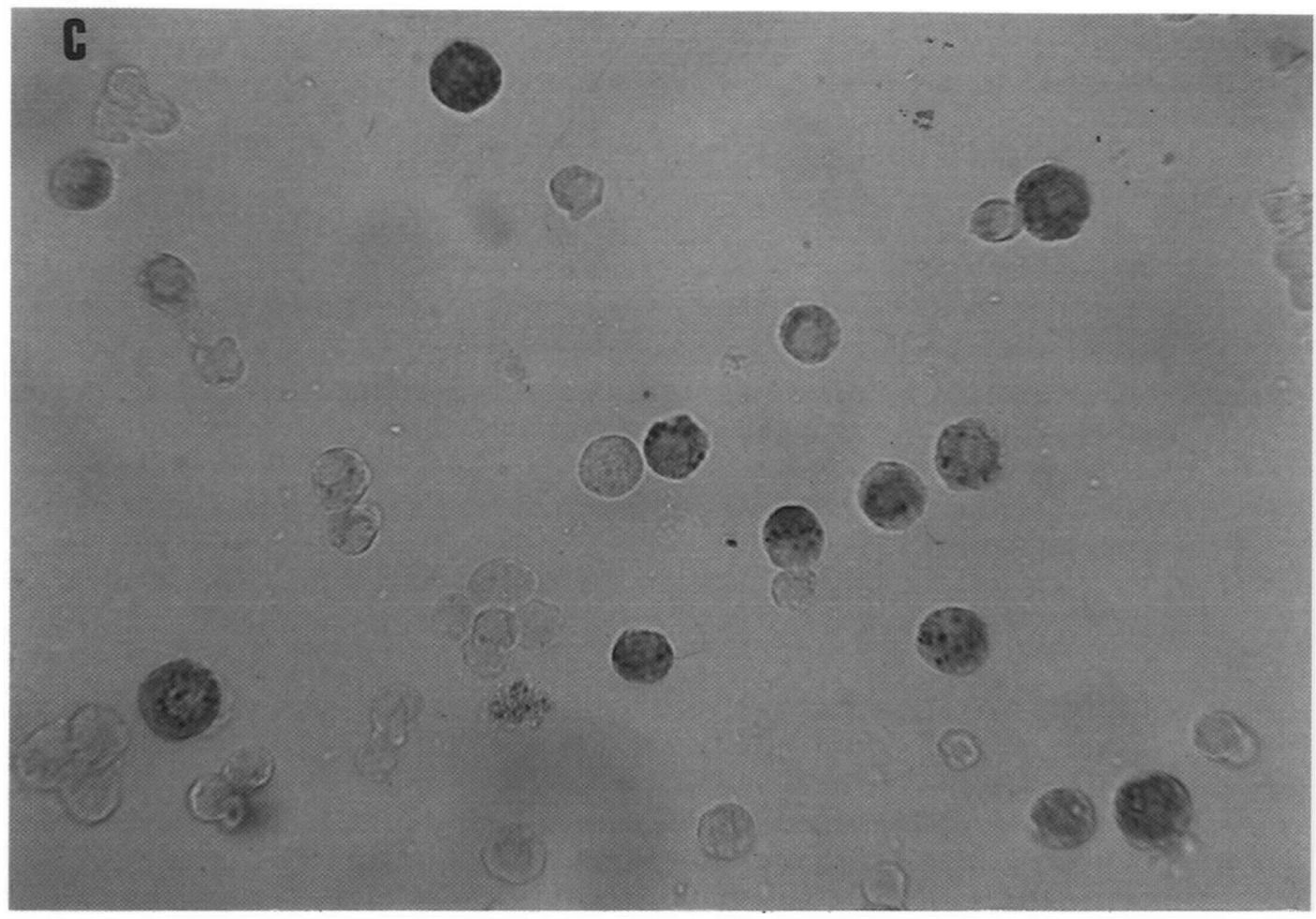

D mRNA

actin

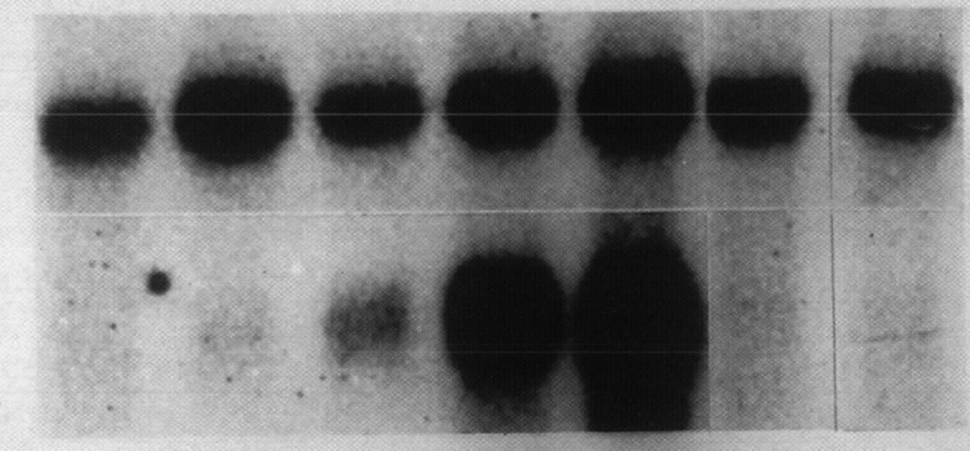

GTH-II

alpha

control $2 d \quad 4 d \quad 7 d \quad 2 w \quad 6 w \quad 10 w$

time after steroïds implantation

Figure 3 (Photos C et D) 
Figure 3 : Illustration de méthodes variées d'investigation endocrinienne chez l'anguille.

Photo A : Etude in vivo : prélèvement sanguin réalisé au moyen d'un cathéter.

Photo B : Etude in vitro sur organe isolé : perfusion d'arcs branchiaux pour l'étude des flux de calcium.

Flèches rouges : entrée du milieu de perfusion dans les arcs branchiaux; flèches bleues : sortie du milieu à partir des arcs branchiaux ou des chambres de perfusion.

Photo C : Etude in vitro sur cellules isolées : culture primaire de cellules hypophysaires.

Les cellules gonadotropes sont marquées (marron foncé) par immunocytochimie au moyen d'un anticorps reconnaissant l'hormone gonadotrope.

Photo D : Analyse par "Northern Blot" des ARN messagers des sousunités $\alpha$ et $\beta$ de l'hormone gonadotrope, extraits à partir des hypophyses d'anguilles ayant reçu un implant stéroïdien.

Les stéroïdes provoquent une augmentation des taux d'ARN codant pour les sous-unités $\alpha$ et $\beta$ de l'hormone gonadotrope (GTH-II) jusqu'à deux semaines $(2 \mathrm{w})$ après implantation ; l'ARN de l'actine sert de référence.

Figure 3 : Illustration of various methods for endocrine investigation in the eel.

Photo A : In vivo study : blood sampling using a catheter.

Photo B : In vitro study on isolated organ: perfusion of gill arches for studying calcium exchanges.

Red arrows : perfusion medium inlet into gill arches ; blue arrows: medium outlet either from gill arches or from perfusion chambers.

Photo $\mathrm{C}$ : In vitro study on isolated cells : primary culture of pituitary cells. Gonadotropic cells are labelled (dark brown) by immunocytochemistry, using an antibody recognizing gonadotropic hormone.

Photo D : "Northern Blot» analysis of gonadotropin $\alpha$ and $\beta$ subunit messenger RNAs, after extraction of pituitaries from steroïd implanted eels.

Steroïds induce an increase in gonadotropin (GTH-II) $\alpha$ and $\beta$ subunit messenger RNAs up to two weeks (2w) after implantation; actin RNA is used as a reference. 
1994). De plus, la possibilité d'effectuer des prélèvements de sang sur des anguilles cathétérisées permet de suivre les variations de taux sanguins hormonaux pouvant dépendre de la photopériode, en travaillant sous lumière rouge de faible intensité, pendant la période d'obscurité (pour l'hormone gonadotrope : DUFOUR, 1985 ; pour la mélatonine : S. DUFOUR, N. LE BELLE et B. VIVIEN, données inédites).

Des équipements plus complexes sont nécessaires pour l'étude de l'effet de facteurs environnementaux plus originaux : par exemple, les caissons hyperbares permettent de faire varier la pression hydrostatique, l'adjonction d'un système de renouvellement d'eau sous pression ouvrant la voie à des expérimentations à long terme (exemple de l'équipement du groupe de recherche de L. BARTHELEMY, Laboratoire de Physiologie de la Faculté de Médecine de Brest : SEBERT et al., 1990).

\subsection{Etudes in vivo sur le terrain}

Les études endocriniennes sur le terrain peuvent avoir des objectifs variés fondamentaux ou appliqués, descriptifs ou expérimentaux.

D'un point de vue descriptif, des prélèvements effectués sur le site même de capture permettent la détermination des taux hormonaux dans les conditions environnementales naturelles. Nous abordons actuellement avec le CSP une étude sur le terrain des modifications anatomiques et endocriniennes liées à l'argenture. D'un point de vue fondamental, une telle étude peut apporter les premiers éléments concernant les variations chez l'anguille d'hormones impliquées dans ce phénomène de métamorphose (voir article de Y.A. FONTAINE, ce numéro) ; d'un point de vue appliqué, elle peut permettre l'élaboration d'outils (tests hormonaux) de caractérisation des populations d'anguilles dans les eaux continentales. La possibilité de réaliser relativement aisément des prélèvements sanguins chez l'anguille, ajoutée aux techniques récentes de dosages immunoenzymatiques, ouvre la voie à la mise en œuvre de ces tests sur le terrain même.

D'un point de vue expérimental, l'étude de l'effet de certains facteurs externes peut nécessiter des expérimentations sur le terrain : c'est le cas des expériences d'immersion en mer profonde qui ont été réalisées afin de rechercher l'effet, à long terme, d'une pression hydrostatique élevée sur la production d'hormone gonadotrope hypophysaire (DUFOUR et FONTAINE, 1985 et voir article de S. DUFOUR, ce numéro).

\section{Etudes in vitro}

\subsection{Intérêt propre des études in vitro}

Les études in vitro permettent la mise en évidence d'une régulation hormonale ainsi que l'analyse de ses mécanismes, à l'échelle de l'organe, de la cellule ou de la molécule. L'isolement d'un organe, ou de cellules, les soustrait à l'ensemble des régulations qui interagissent normalement in vivo. Cette simplification est nécessaire à l'étude et l'analyse de chaque régulation ; cependant, elle risque aussi de représenter une situation trop éloignée des conditions physiologiques naturelles. C'est pourquoi une confrontation des résultats obtenus in vitro et in vivo est absolument nécessaire pour valider les données obtenues in vitro et les intégrer dans un schéma plus global de régulation.

\subsection{Etudes in vitro sur organes isolés}

Le fonctionnement et la régulation d'organes isolés peuvent être étudiés par des expériences d'incubation (l'organe étant immergé dans un milieu statique) ou de perfusion (l'organe étant immergé dans un flux continu de milieu ou irrigué par un flux continu de milieu dans le cas où la vascularisation de l'organe peut être utilisée et cathétérisée).

Des expériences d'incubation de petits fragments d'ovaires d'anguilles ont été mises en oeuvre au Laboratoire et ont permis d'étudier les capacités stéroïdogènes de l'ovaire : les tissus sont incubés avec différents précurseurs de la chaîne de biosynthèse des hormones stéroïdes et on recherche quels dérivés ont pu être produits dans les extraits de tissus et dans le milieu. Ces études permettent d'observer les modifications des capacités stéroïdogènes de l'ovaire entre les stades jaune et argenté ainsi qu'au cours de diverses expérimentations (LELOUP-HATEY et al., 1985). 
Ce même dispositif a permis d'étudier le mécanisme de l'action de l'hormone gonadotrope sur l'ovaire: des fragments d'ovaires incubés avec de l'hormone gonadotrope produisent un second messager intracellulaire, l'adénosine monophosphate cyclique $(A M P c)$ qui est également le second messager des hormones gonadotropes chez les Mammifères. L'AMPc est dosée dans les extraits de tissus et dans le milieu d'incubation. Le dosage de l'AMPc des échantillons est réalisé par une réaction de compétition, similaire à un dosage radioimmunologique mais mettant en jeu, à la place de l'anticorps, une protéine de liaison spécifique de l'AMPc et isolée à partir du muscle de lapin. Ces expériences ont permis d'analyser le mécanisme d'action de la GTH pour la première fois chez un poisson et offrent également la possibilité d'un dosage biologique de l'activité gonadotrope, la production d'AMPc étant corrélée à la dose d'hormone (FONTAINEBERTRAND et al., 1978).

Des expériences de perfusion ont été réalisées pour l'étude de la régulation hormonale des flux de calcium à travers la branchie (Figure 3 : Photo B). La préparation d'arc branchial isolé a été mise au point au Laboratoire pour étudier les flux unidirectionnels (flux entrant et flux sortant) de calcium. Elle permet de mesurer les modifications de ces flux à la suite de l'ablation de glandes endocrines (par exemple, les Corpuscules de Stannius) et de mettre en évidence les effets de la perfusion de différentes préparations d'extraits de ces glandes. L'étude de la vascularisation des arcs branchiaux, en utilisant des résines, nous a permis de mettre au point un système de cathétérisation. Six arcs branchiaux ainsi préparés sont suspendus dans des chambres individuelles contenant le milieu extérieur. Trois d'entre eux sont utilisés pour la mesure du flux entrant (l'isotope ${ }^{45} \mathrm{Ca}$ est placé dans le milieu extérieur et mesuré dans le milieu effluent), les trois autres pour la mesure du flux sortant (l'isotope est placé dans le milieu de perfusion et mesuré dans des aliquots du milieu extérieur). Le débit de perfusion $(0,1 \mathrm{ml} / \mathrm{min}$.) a été choisi après détermination in situ du débit sanguin à travers l'arc. Ce dispositif expérimental nous a permis de montrer que l'ablation des corpuscules de Stannius chez l'anguille, en augmentant le flux entrant branchial de calcium et en réduisant le flux sortant, est responsable de l'hypercalcémie observée in vivo. La perfusion d'extraits de ces glandes modifient les flux de calcium dans le sens d'une restauration d'une normocalcémie. La perfusion du fragment synthétique 1-34 de l'hormone parathyroïdienne humaine (1-34 hPTH) montre que celui-ci agit sur les flux de calcium de manière analogue à l'hormone des corpuscules de Stannius de l'anguille. Ainsi, il a été possible d'établir qu'il existait une analogie de fonction entre ces deux hormones en plus d'une similitude de structure (MILET et al., 1985).

\subsection{Etudes in vitro sur cellules isolées}

Des expériences sont réalisées sur des cellules obtenues par dissociation des tissus et mise en culture. Ces cellules, qui peuvent être maintenues en survie pendant deux à trois semaines et qui conservent leur différenciation initiale, sont qualifiées de cultures primaires.

Les techniques de dissociation enzymatique et de culture des hépatocytes d'anguille ont été mises au point par BURZAWA-GERARD et collaborateurs : ces cultures permettent d'étudier les mécanismes de l'interaction entre les hormones stéroïdes et l'hormone de croissance dans le contrôle de la production de vitellogénine (voir article de E. BURZAWAGERARD et al., ce numéro).

Nous avons aussi mis au point les techniques de dissociation et culture des cellules hypophysaires d'anguille (Figure 3 : Photo $\mathrm{C}$ ). Ces cultures nous permettent d'étudier les mécanismes des contrôles exercés par les neurohormones cérébrales et les hormones périphériques sur la production des hormones hypophysaires (DUFOUR et al., 1992).

L'utilisation de cultures primaires offre de nombreux avantages :

- La maîtrise des facteurs de régulation en présence dans le milieu de culture permet d'analyser séparément l'effet de chaque régulateur potentiel puis d'en étudier les interactions. La dissociation des cellules permet également un accès aux cellules très rapide des facteurs de régulation placés dans le milieu, condition indispensable aux études à très court terme des cinétiques d'action et de production des seconds messagers intracellulaires. 
- D'un point de vue pratique, l'homogénéité des lots expérimentaux (réalisés à partir de la répartition d'une même préparation de cellules dispersées) permet d'éviter, au sein d'une expérience, le problème de la variabilité individuelle des réponses (variabilité qui est importante dans le cas d'un animal sauvage comme l'anguille). La possibilité de travailler sur un nombre réduit de cellules par puits de culture permet aussi de limiter le nombre d'animaux utilisés dans une expérience par rapport aux expérimentations in vivo (ce qui est important également pour un animal à protéger comme l'anguille).

Cependant, les conditions artificielles de ces cultures telles que l'absence des contacts cellulaires membranaires se produisant normalement dans le tissu et l'absence de l'ensemble des facteurs de régulation (locaux ou circulants) peuvent entraîner d'importantes modifications dans les réponses des cellules aux facteurs étudiés. II reste donc toujours essentiel de confronter les résultats ainsi obtenus in vitro aux données d'expérimentations in vivo.

\subsection{Etudes in vitro subcellulaires}

On évoquera brièvement tout le domaine d'études réalisées au niveau subcellulaire, c'est à dire à l'échelle des constituants moléculaires de la cellule. Ce domaine d'investigation inclut l'ensemble des études d'interactions moléculaires impliquées dans la production et l'action hormonale telles que l'association hormone-récepteur, l'association récepteur-élément de régulation nucléaire, etc...

Chez l'anguille, on peut citer par exemple les études de caractérisation de récepteurs hormonaux : récepteurs membranaires ovariens de l'hormone gonadotrope, (SALMON et al.,1987); récepteurs cytosoliques et nucléaires hépatiques de l'estradiol (voir article de E. BURZAWA-GERARD et al., ce numéro).

\section{CONCLUSION}

L'étude endocrinienne d'une espèce sauvage, comme l'anguille, nécessite la mise au point de toute une panoplie de méthodes d'investigation, depuis les expériences à l'échelle moléculaire jusqu'aux études in vivo sur le terrain. Cet ensemble d'approches représente la condition indispensable à une étude physiologique intégrée de ce poisson aussi bien du point de vue de la recherche fondamentale que des points de vue appliqués de la caractérisation, gestion et maîtrise de ses populations.

\section{REMERCIEMENTS}

Nous remercions les membres du Laboratoire, en particulier M. FONTAINE, Y.A. FONTAINE, N. LE BELLE, A. HARDY, B. VIDAL, M. MONTERO, B. PRADET-BALADE, E. BURZAWA-GERARD, S. BALOCHE, E. FONTAINE-BERTRAND, J. LELOUP, J. LELOUPHATEY, E. LOPEZ, A. DE LUZE ainsi que nos nombreux collaborateurs en France et à l'étranger, qui ont permis le développement de ces études. Nos remerciements vont également au MNHN, CNRS, CSP, DRED, IFREMER, INRA qui ont soutenu ou soutiennent financièrement ces travaux.

\section{BIBLIOGRAPHIE}

BRUSLE J., 1990. L'Anguille européenne, Anguilla anguilla, une espèce jugée commune jusqu'à la dernière décennie, mérite-t-elle d'acquérir aujourd'hui le statut d'espèce menacée? Bull. Soc. Zool., 114, 61-73.

BURZAWA-GERARD E., 1971. Purification d'une hormone gonadotrope hypophysaire de poisson téléostéen, la Carpe (Cyprinus carpio L.). Biochimie, 53 , 545-552.

BURZAWA-GERARD E., KERDELHUE B., 1978. Etude par radioimmunologie des propriétés des immunosérums de l'hormone gonadotrope de la Carpe (Cyprinus carpio) et de ses sous-unités. Ann. Biol. anim. Bioch. Biophys., 18, 773-780. 
BURZAWA-GERARD E., BALOCHE S., LELOUP-HATEY J., LE MENN F., MESSAOURI H., NUNEZ-RODRIGUEZ J., PEYON P., ROGER C., 1994. Ovogenèse chez l'anguille, (Anguilla angúllla L.) : ultrastructure de l'ovaire à différents stades de développement et implication des lipoprotéines au cours de la vitellogenèse. Bull. Fr. Pêche Piscic., 335.

CARDINAUD B., QUERAT B., DUFOUR S., VINCENT J.D., VERNIER P., 1994. The molecular diversity of dopamine receptors expressed in the eel brain and pituitary. $I n$ : "Abstracts from the 17th Conference of European Comparative Endocrinologists", University of Cordoba, Spain.

DUFOUR S., 1985. La fonction gonadotrope de l'anguille européenne, Anguilla anguilla L., au stade argenté (au moment du départ pour la migration de reproduction) : les mécanismes de son blocage et sa stimulation expérimentale. Thèse de Doctorat d'Etat, MNHN/Univ. Paris VI, $158 \mathrm{p}$.

DUFOUR S., 1986. La saga des anguilles. La Recherche, 182, 1456-1459.

DUFOUR S., 1994. Neuroendocrinologie de la reproduction de l'anguille : de la recherche fondamentale aux problèmes appliqués. Bull. Fr. Pêche Piscic., 335.

DUFOUR S., DELERUE-LE BELLE N., FONTAINE Y.A., 1983. Development of a heterologous radioimmunoassay for eel (Anguilla anguilla) gonadotropin. Gen. Comp. Endocrinol. 49, 404-413.

DUFOUR S., FONTAINE Y.A., 1985. La migration de reproduction de l'anguille européenne (Anguilla anguilla L.) : un rôle probable de la pression hydrostatique dans la stimulation de la fonction gonadotrope. Bull. Soc. Zool. Fr., 110, 291-299.

DUFOUR S., LE BELLE N., BALOCHE S., FONTAINE Y.A., 1989. Positive feedback control by the gonads on gonadotropin (GTH) and gonadoliberin $(\mathrm{GnRH})$ levels in experimentally matured female silver eels, Anguilla anguilla. Fish Physiol. Biochem., 7, 157-162.

DUFOUR S., LE BELLE N., VIDAL B., MONTERO M., PORTAL I., BASSOMPIERRE M., 1992. Primary cultures of pituitary cells from normal and estradiol-treated female silver eels (Anguilla anguilla) immunocytochemical characterization of gonadotropic cells and stimulation of gonadotropin release. In: "Abstracts from the 16th Conference of European Comparative Endocrinologists", University of Padova, Italy.

DUFOUR S., MONTERO M., LE BELLE N., BASSOMPIERRE M., KING J.A., MILLAR R.P., PETER R.E., FONTAINE Y.A., 1993. Differential distribution and response to experimental sexual maturation of two forms of brain gonadotropin-releasing hormone $(\mathrm{GnRH})$ in the European eel, Anguilla anguilla. Fish Physiol. Biochem., 11, 99-106.

FONTAINE Y.A., 1994. L'argenture de l'anguille : métamorphose, anticipation, adaptation. Bull. Fr. Pêche Piscic., 335.

FONTAINE-BERTRAND E., SALMON C., FONTAINE Y.A., 1978. Effet d'hormones gonadotropes in vitro, sur la concentration de l'adénosine monophosphate cyclique dans l'ovaire de l'Anguille (Anguilla anguilla L.). Ann. Biol. anim. Bioch. Biophys., 18, 805-811.

LELOUP J., DE LUZE A., 1980. Prolactine et hormones thyroïdiennes chez l'anguille (Anguilla anguilla L.). C. R. Acad. Sci. Paris, Sér D, 291, 87-90.

LELOUP-HATEY J., 1964. Fonctionnement de l'interrénal antérieur de deux Téléostéens : le saumon atlantique et l'anguille européenne. Ann. Inst. Oceanogr. Monaco, 42, 224-337.

LELOUP-HATEY J., 1976. Méthodes de mesure des vitesses d'épuration métabolique et de sécrétion du cortisol chez l'anguille (Anguilla anguilla L.). Can. J. Physiol. Pharmacol., 54, 262-276.

LELOUP-HATEY J., FONTAINE Y.A., DUFOUR S., QUERAT B., 1985. Rôle des stéroïdes et des facteurs externes dans le contrôle de la fonction gonadotrope hypophysaire de l'anguille européenne (Anguilla anguilla L.) femelle. In : "Bases biologiques de l'Aquaculture", IFREMER, Actes de Colloques, 1, 309-320. 
MARCHELIDON J., HUET J.C., SALMON C., PERNOLLET J.C., FONTAINE Y.A., 1991. Purification et caractérisation des sous-unités présumées de l'hormone thyréotrope d'un poisson téléostéen, l'anguille (Anguilla anguilla). C. R. Acad. Sci. Paris, Sér III, $313,253-258$.

MARCHELIDON J., HOUDEBINE L.M., LE BELLE N., DUFOUR S., 1994. Development and application of a radioimmunoassay for European eel (Anguilla anguilla L.) growth hormone. In: "Abstracts from the 17th Conference of European Comparative Endocrinologists", University of Cordoba, Spain.

MEDINA M., REPERANT J., DUFOUR S., WARD R., LE BELLE N., MICELI D., 1994. The distribution of GABA-immunoreactive neurons in the brain of the silver eel (Anguilla anguilla L.). Anat. Embryol., 189, 25-39.

MILET C., HILLYARD C.J., MARTELLY E., CHARTIER M.M., TISSERAND-JOCHEM S., GIRGIS S., MACINTYRE I., LOPEZ E., 1985. The eel corpuscules of Stannius secrete a molecule resembling mammalian parathyroid hormone. In B. LOFTS \& W.N. HOLMES (eds) "Current Trends in Comparative Endocrinology" , pp 827-830, Hong-Kong University Press.

MONTERO M., VIDAL B., KING J.A., TRAMU G., VANDESANDE F., DUFOUR S., KAHO., sous presse. Immunocytochemical localization of mammalian $\mathrm{GnRH}$ (gonadotropinreleasing hormone) and chicken GnRH-II in the brain of the European silver eel (Anguilla anguilla L.). J. Chem. Neuroanat.

PRADET-BALADE B., 1994. Expression des ARNm des sous-unités $a$ et $b$ de la TSH chez un téléostéen, l'anguille argentée : contrôle par les hormones thyroïdiennes. DEA d'Endocrinologie et intercations cellulaires, Université Paris-Sud, 27 p.

QUERAT B., 1994. Molecular evolution of the glycoprotein hormones in vertebrates. In : "Perspectives in Comparative Endocrinology", National Research Council of Canada, pp 27-35.

QUERAT B., JUTISZ M., FONTAINE Y.A., COUNIS R., 1990a. Cloning and sequence analysis of the cDNA for the pituitary glycoprotein hormone a-subunit of the European eel. Mol Cell Endoc., 71, 253-259.

QUERAT B., MOUMNI M., JUTISZ M., FONTAINE Y.A., COUNIS R., 1990b. Molecular cloning and sequence analysis of the cDNA for the putative $b$ subunit of the type II gonadotrophin from the European eel. J. Mol. Endoc., 4, 257-264.

QUERAT B., HARDY A., FONTAINE Y.A., 1991. Regulation of type-II gonadotrophin a and b subunit mRNAs by estradiol and testosterone in the European eel. J. Mol. Endoc., 7, 81-86.

QUERAT B., CARDINAUD B., HARDY A., VIDAL B., D'ANGELO G., 1994. Sequence and regulation of European eel prolactin mRNA. Mol. Cell. Endoc., 102, 151-160.

SAITO A., SEKINE S., KOMATSU Y., SATO M., HIRANO T., ITOH S., 1988. Molecular cloning of eel growth hormone and its expression. In Escherichia coli. Gene, 73, 545-555.

SALMON C., MIYASHITA Y., MARCHELIDON J., FONTAINE Y.A., 1987. Mise en évidence des propriétés des sites de liaison spécifique pour la gonadotropine de carpe dans les préparations membranaires d'ovaire d'Anguille (Anguilla anguilla L.). Gen. Comp. Endocrinol., 65, 203-211.

SALMON C., MARCHELIDON J., FONTAINE Y.A., HUET J.C., QUERAT B., 1993. Clonage et séquence de la sous-unité $b$ de la thyrotropine d'un poisson téléostéen, l'anguille (Anguilla anguilla L.). C. R. Acad. Sci. Paris, Sciences de la Vie, 316, 749-753.

SEBERT P., BARTHELEMY L., SIMON B., 1990. Laboratory system enabling long-term exposure (>30d) to hydrostatic pressure $(<101 \mathrm{~atm})$ of fishes or other animals breathing water. Mar. Biol., 104, 165-168. 